\title{
Relationship of Self-Regulation Learning and Academic Stress among First Year Students at Faculty of Nursing University of Jember
}

\author{
Rista Dwi Pratiwi ${ }^{\star}$, Erti lkhtiarini Dewi², Enggal Hadi Kurniyawan ${ }^{3}$
}

${ }^{1}$ Nursing Student, Faculty of Nursing, Universitas Jember, Indonesia; ristadwi468@gmail.com (Corresponding Author)

2,3Psychiatric nursing department, Faculty of Nursing, Universitas Jember, Indonesia

\begin{tabular}{ll}
\hline Article Info: & ABSTRACT \\
\cline { 2 - 3 } Submitted: & The increase self-regulation learning has an important role related to academic stress \\
10-06-2021 & management. First-year students are faced with various academic rules and demands \\
Revised: & that cause first year students to be stressed. This research analyze the correlation \\
09-07-2021 & between self-regulation learning and academic stress of first-year students of the \\
Accepted: & Faculty of Nursing, University of Jember. This research method is a cross-sectional \\
09-07-2021 & study of 126 first-year students using cluster random sampling techniques. Bivariate \\
& analysis using Kendall tau b correlation $(a<0.05 \mathrm{Cl}=95 \%)$. The research instruments \\
& used were Self-Regulated Learning (Cronbach Alpha $=0.864)$ and Educational Stress \\
& Scale for Adolescents (Cronbach Alpha $=0.849)$. The result of Kendall tau b \\
& correlation test results show p-value $0.015(a<0.05)$ and $\tau=-0.150$. This study found \\
DOI: & that self-regulation learning correlated to academic stress first-year students of the \\
https://doi.org/10.53713/nhs.v1i1.21 & Faculty of Nursing, University of Jember. The correlation results showed a negative \\
& relationship direction with very weak strength, the higher self-regulation learning, the \\
& lower level of perceived academic stress. From the results and conclusions, researcher \\
& hopes that of first-year nursing faculty students can make more efforts to improve self- \\
& regulation learning process as an effort to deal with various problems during the lecture \\
& period. The existence of self-regulation in learning that is more optimal, the student will \\
& not feel burdened by academic demands so that students can adjust to all lecture \\
& processes and are able to manage quite a lot of burden without any pressure.
\end{tabular}

This work is licensed

under CC BY-SA License.

Keywords: academic stress, first year nursing student, self regulation learning

\section{INTRODUCTION}

First-year students are faced with many changes in the new education system that make first-year students required to be able to adapt from a variety of changes. First-year students are included in the transition period from high school to college. From this transition period, students will face changes that occur in college. In the 2020 school year the national lecture learning process is conducted from home online (Learning from home) (Sudarsana et al., 2020). So that the education system in universities in the teaching and learning process is done remotely from home, it applies during the emergency of the Covid-19 pandemic (Kemendikbud RI, 2020). The new learning system that has been implemented makes a big impact in college, especially those felt by first-year students in their first year of study. Firstyear students are in a transition period that is faced by many new things that make first-year students required to be able to adapt to new rules and in a learning process that is different from before with very different rules from high school to college, it can trigger the occurrence of stress arising from various demands both academic and non-academic.

This study shows that self-regulation learning can minimize academic stress experienced by first-year students. Self-regulation learning can affect individual changes in the thought process for the better than before, feelings and actions that have been designed and the response that has been adjusted from the achievement of the individual's own goals (Gufron \& Risnawita 2010). First-year students are included in their late teens who experience many changes or emotional instability in dealing with a problem. Therefore, first-year students find it easier and often experience academic stress which can have an impact on less than optimal academic performance (Saraswati et al., 2020). Olejnik (2007 in Saffira et al., 2017) states that academic stress is a response that arises because of the many demands and tasks that must be done by students. One of the efforts to reduce students' academic stress levels is with good and effective time management. Davidson (2001 in Saffira et al., 2017) says that time management can complete work in a structured and controlled manner, so that the results achieved are in line with expectations and are felt more quickly. If time is not used 
properly, it is possible that time can hinder success. So in meeting the various demands experienced by students, selfregulation in good learning is needed. With self-regulation learning, a person has confidence in determining achievement, self-evaluation, self-monitoring to organize and plan time which can make an important contribution to achieving academic achievement (Dami \& Parikaes, 2018). Self-regulation skills in learning will be able to reduce the level of academic stress in students. This is in line with the analysis of Rena's research (2018) which confirms that selfregulation learning has proven to be effective in coping with academic stress.

In the world of lectures to face academic demands and pressures, students must try well in adjusting, such demands can be such as a change in style in studying from high school to college, time of use of learning, fear in facing exams, tasks that accumulate and must be completed according to deadlines, critical thinking, academic achievement, low test scores, rules that are difficult to accept in transition, determination of majors and careers, and demands in processing time. This makes students feel a lot of demands and experience stress, stress that is often experienced by students, namely stress that comes from academics (Saniskoro \&Akmal, 2017). First-year students are included in late adolescence who experience many changes or emotional instability in the face of a problem, therefore it is easier to experience academic stress that can impact on academic performance that is less than optimal (Saraswati et al., 2020).

Based on the data of the survey conducted by the American College Health Association (ACHA) in 2018 involving 26,181 respondents, $31.9 \%$ experienced stress caused by the impact of academic processes. Academic stress experienced by students is influenced by skills in managing time in learning with other activities (Sagita et al., 2017). Liu's research (2011) gave the results of most of the research subjects as much as $90 \%$ experienced academic stress triggered by the number of tasks given, test scores, achievements that did not meet, delaying the work of assignments, the changing school climate and confidence and the desire to learn, deadlines of tasks collected on the adjacent day.

The statement is in accordance with the results of preliminary studies through unstructured interviews online at first-year students of the Faculty of Nursing, University of Jember. A total of 5 students stated that there is a difference away from the learning system given and the first-year student stated that he was experiencing stress. This is because it is faced by too much task load, too many task deadlines and close proximity to other tasks, strict rules and different from other faculties, lack of mastering the lecture materials delivered by lecturers so that individuals do not fully follow the learning process well and maximally, online learning encounters many obstacles such as network and signal constraints, the tight schedule of lectures. Of the 5 students, 2 of them said to experience severe stress until the time of doing the task while crying it is due to the number of tasks coupled with difficult tasks. As for self-regulation learning obtained results from interviews through online media as many as 5 students said to overcome the difficulties that are facing is to use learning strategies such as doing tasks far from the deadline specified, asking lecturers during lectures, asking friends if there are materials that do not understand and looking for other literature.

The many demands of academic burden, students are required to be able to strive in managing time as best as possible, arrange activities and can assess their ability, if it is done it will be able to minimize the occurrence of academic stress (Damri et al., 2017). Students who are unable to adjust to academic demands will have a high level of stress while students who can adjust in the face of academic demands on average have low stress. The number of first-year students who have not been able to adjust their learning strategies to the demands of lectures and cannot manage the learning time as best as possible, then it makes students experience academic stress (Nurfitriana, 2016). This is the basis of students in using Self-Regulated Learning (SRL) learning strategies to minimize the occurrence of academic stress. Self-regulation learning (SRL) plays an important and indispensable role in managing academic stress and can support academic achievement during education. Self-regulation learning $(\mathrm{SRL})$ is a systematic process carried out by a person in directing thoughts, feelings and actions to achieve academic success. The role of self-regulation learning is as a regulator of learning by using strategies in planning, monitoring, controlling and evaluating oneself systematically in achieving a learning goal. Students who have SRL will be able to be useful in arranging every lecture activity so that the chances of academic stress will be lower.

Based on the phenomenon that has been described researchers are interested to find out more related to "Relationship of Self-Regulation Learning with Academic Stress in First-Year Students of the Faculty of Nursing, University of Jember". It aims to know the self-regulation in the learning process and the level of academic stress felt by first-year students of the Faculty of Nursing University ofJember. 


\section{METHOD}

Design of this study is quantitative correlation with Cross Sectional approach, in data retrieval is done momentarily in just one time and collected simultaneously. The research population is all first-year students of the Faculty of Nursing, University of Jember class 2020/2021 with a total of 183 students. Sampling technique used is probability sampling with cluster random sampling method. The total sample used in this study was 126 first-year students of the Faculty of Nursing, University of Jember. The sample criteria in this study include inclusion criteria including willingness to be a respondent in the research and first-level students (2020/2021) Faculty of Nursing, University of Jember. The exclusion criteria are students over level. Filling out the questionnaire through google form link includes Self-Regulated Learning questionnaire amounting to 38 question item with cronbach Alpha $=0.864$ (Agustina, 2016) and Educational Stress Scale for Adolescents questionnaire amounting to 14 item questions with cronbach Alpha $=0.849$ (Rahmawati, 2020). Data collection was conducted on February 25, 2021. The data analysis used a correlation test of Kendall tau $b(p<0.05)$. This research was conducted an ethics test at the Faculty of Nursing, University of Jember and was declared to pass the ethics through the KEPK Faculty of Nursing, University of Jember with the No. 18/UN25.1.14/KEPK/2021.

\section{RESULT}

\section{Characteristics of Respondents}

Table 1. Distribution of Characteristics of First-Level Student Respondents of the Faculty of Nursing, University of Jember.

\begin{tabular}{ccc}
\hline Characteristics & Frequency & Percentage \\
\hline Gender & & \\
Male & 21 & 16,7 \\
Female & 105 & 83,3 \\
\hline Major Selection & & \\
First & 76 & 60,3 \\
second & 46 & 36,5 \\
Third & 4 & 3,2 \\
\hline & median & Min-max \\
\hline Age (years) & 19 & $16-20$ \\
\hline
\end{tabular}

Based on table 1, it can be known that the results of the distribution of characteristics of first-year student respondents of the Faculty of Nursing, University of Jember showed that respondents with more female gender compared to men with a ratio of 105 respondents (83.3\%) women and 21 (16.7\%) man. Characteristics of respondents based on the period of selection of majors many students choose the department of the Faculty of Nursing in the first place, namely with the number of 76 respondents $(60.3 \%)$. Based on the age of respondents entering the late adolescence that ranges in age from 16 to 20 years.

\section{Overview of Self-Regulation Learning of First-Year Students of the Faculty of Nursing, University of Jember}

Table 2. Descriptive Analysis of Self-Regulation in the Study of First-Level Students of the Faculty of Nursing, University of Jember.

\begin{tabular}{lcc}
\hline \multicolumn{1}{c}{ Variable } & Mean & SD \\
\hline Self Regulation Learning & 138.38 & 16.66 \\
Metacognitive & 68.98 & 9.25 \\
Motivation & 38.34 & 4.40 \\
Active Behavior & 31.07 & 4.25 \\
\hline
\end{tabular}

Based on table 2 shows that the distribution of respondents to self-regulation in the study of first-level students of the Faculty of Nursing, University of Jember obtained a mean value of 138,38 with a standard deviation of 16 . This is because the standard deviation is a very high mirroring of deviations, so the dissemination of data shows normal results and does not cause bias. While the standard deviation of each indicator averages close to 0 and below the mean value, the standard deviation is a reflection of the mean value if the standard deviation is greater than the mean value then it 
indicates a poor representation of the data, and vice versa. On self-regulation indicators in learning that have the highest average value is the metacognition indicator while the lowest indicator is on the behavioral indicator.

Table 3. Levels of Self-Regulation Learning for First Level Students of the Faculty of Nursing, University of Jember.

\begin{tabular}{|c|c|c|}
\hline Level of Self-Regulation Learning & Frequency & Percentage \\
\hline Very low & 0 & 0 \\
\hline Low & 1 & 8 \\
\hline Medium & 31 & 24.6 \\
\hline High & 82 & 65.1 \\
\hline Very high & 12 & 9.5 \\
\hline Total & 126 & 100 \\
\hline
\end{tabular}

Based on table 3, it can be seen that most of the first-year students of the Faculty of Nursing, Jember University, as many as 82 respondents $(65.1 \%)$ have a high level of self-regulation learning. There are no first-year students who have a very low level of self-regulation learning.

\section{Overview of Academic Stress of First-Year Students of the Faculty of Nursing, University of Jember}

Table 4. Descriptive analysis of academic stress of first year students of the Faculty of Nursing, University of Jember.

\begin{tabular}{lcc}
\hline \multicolumn{1}{c}{ Variable } & Mean & SD \\
\hline Academic Stress & 45.76 & 7.08 \\
Pressure from study & 8.82 & 2.41 \\
Workload & 8.67 & 2.24 \\
Worry about grades & 7.94 & 1.53 \\
Self-expectation & 11.39 & 2.24 \\
Despondency & 8.94 & 1.94 \\
\hline
\end{tabular}

Based on table 4 shows that the distribution of respondents on the academic stress of first-year students of the Faculty of Nursing, University of Jember with an average score of 45.76 with a standard deviation of 7.08 means that the mean value is greater than the standard deviation so as to indicate that the results are quite good. This is because the standard deviation is a very high mirroring of deviations, so the dissemination of data shows normal results and does not cause bias. While the standard deviation of each indicator averages close to 0 and below the mean value, the standard deviation is a reflection of the mean value if the standard deviation is greater than the mean value then it indicates a poor representation of the data, and vice versa. In academic stress indicators that have the highest average score is the Self-expectation indicator while the lowest indicator is on the Worry about grades indicator.

Table 5. Academic Stress Levels of First Year Students of the Faculty of Nursing, University of Jember.

\begin{tabular}{|c|c|c|}
\hline Academic Stress Level & Frequency & Percentage \\
\hline Very low & 32 & 25.4 \\
\hline Low & 37 & 29.4 \\
\hline Medium & 37 & 29.4 \\
\hline High & 20 & 15.9 \\
\hline Very high & 0 & 0 \\
\hline Total & 126 & 100 \\
\hline
\end{tabular}

Based on table 5, it appears that first-year students of the Faculty of Nursing, University of Jember mostly experienced low academic stress levels as many as 37 respondents (29.4\%) and moderate academic stress levels of 37 respondents (29.4\%). There are no first-year students who experience very high academic stress. 
Analysis of The Relationship of Self-Regulation learning with Academic Stress in First-Year Students of the Faculty of Nursing, University of Jember.

Table 6. Results of Analysis of the Relationship between Self-Regulation Learning and Academic Stress in First Year Students of the Faculty of Nursing, University of Jember.

\begin{tabular}{cccc}
\hline Variable & $(\tau)$ & $\mathrm{p}$ value & Correlation direction \\
\hline Self-Regulation Learning-Academic Stress & -0.150 & 0.015 & Negative \\
\hline
\end{tabular}

Table 6 shows that the results of the analysis using Kendall tau $b$ test obtained the value of $p$ value $=0.015$ with a significance level of $0.05(p<a)$. The value shows that Ha is accepted, namely there is a relationship between selfregulation learning and academic stress in first-year students of the Faculty of Nursing, University of Jember. The correlation value of Kendall tau $b$ ( $(\square)$ obtained -0.150 which means there is a negative relationship with very weak strength, the higher the frequency of self-regulation learning, the lower level of academic stress felt or vice versa.

\section{DISCUSSION}

This study shows that self-regulation learning can minimize academic stress experienced by first-year students. Self-regulation learning can affect individual changes in the thought process for the better than before, feelings and actions that have been designed and the response that has been adjusted from the achievement of the individual's own goals (Gufron \& Risnawita 2010). First-year students are included in their late teens who experience many changes or emotional instability in dealing with a problem. Therefore, first-year students find it easier and often experience academic stress which can have an impact on less than optimal academic performance (Saraswati et al., 2020). Olejnik (2007 in Saffira et al., 2017) states that academic stress is a response that arises because of the many demands and tasks that must be done by students. One of the efforts to reduce students' academic stress levels is with good and effective time management. Davidson (2001 in Saffira et al., 2017) says that time management can complete work in a structured and controlled manner, so that the results achieved are in line with expectations and are felt more quickly. If time is not used properly, it is possible that time can hinder success. So in meeting the various demands experienced by students, selfregulation in good learning is needed. With self-regulation learning, a person has confidence in determining achievement, self-evaluation, self-monitoring to organize and plan time which can make an important contribution to achieving academic achievement (Dami \& Parikaes, 2018). Self-regulation skills in learning will be able to reduce the level of academic stress in students. This is in line with the analysis of Rena's research (2018) which confirms that selfregulation learning has proven to be effective in coping with academic stress.

The results of this study are in line with research conducted by Rahmawati, (2020) in students at the Islamic University of Indonesia concluded a significant relationship of self-regulation learning with academic stress. Another study conducted by Kirana et al., (2016 in Pattynama et al., 2019) by providing self-regulatory interventions in learning has been shown to reduce negative psychological variables, one of which is academic stress. The results of this study showed that the direction of correlation between variables, namely self-regulation learning with academic stress shows the direction of negative relationships, which indicates that the higher self-regulation learning, the more academic stress experienced by first-year students. These results are in line with Trevisani's (2015) study which identified the application of self-regulated learning to stress levels in students where self-regulated learning can significantly lower the level of stress experienced by students. In another study conducted by Arabzadeh et al., (2012) from the results of the analysis showed a negative and significant relationship between variables of self-regulation learning with academic stress. Variables of self-regulation learning directly affect academic stress which indicates that self-regulation learning has influenced academic stress.

Self-regulation learning plays an important role in reducing stress that comes from academics. The level of academic stress experienced by students comes from the urge to go to class, get and complete many assignments, demands to get good test results, anxiety in carrying out exams, and demands in managing study time (Barseli et al., 2017). Self-regulation in learning is the ability possessed by each individual in maintaining thoughts, behavior and emotions in learning activities to achieve academic success, learning new knowledge with initiatives from within (Chirzin, 2018). Self-regulation learning if used properly will be able to help a person in meeting the various demands faced and has a major role in achieving an academic achievement (Rachmah, 2015). The results of this study showed that the correlation strength between self-regulation learning and academic stress in first-year students is very weak. It is seen that most first-year students have a high level of self-regulation learning $65.1 \%)$, but there are still students who experience high academic stress (15.9\%). Therefore, based on the results, the researchers concluded that although self- 
regulation learning is high, they will still be able to experience academic stress both low to high levels. These results can be due to several other factors, which can also affect the decrease in academic stress experienced by first-year students in addition to self-regulation factors in learning.

Yusuf and Jannatul (2020) mentioned that academic stress is influenced by several factors both internal and external factors. Internal factors include self-efficacy, hardiness, optimism, motivation to excel and procrastination. While the external factor is derived from the social support of parents. Self-regulation learning (SRL) is an internal factor included in psychological factors (Friskilia \& Hendri, 2018). Self-regulation learning is one of the factors that can affect academic stress levels (Wulandari, 2018). Another study conducted by Wistarini \& Marheni (2018) stated that family social support and self-efficacy have a role in lowering academic stress levels. Lawson et al., (2019) stated that selfregulation learning among students shows the number of students who do not utilize existing knowledge related to learning strategies. In some cases students do not show awareness about the effectiveness of self-regulation strategies in the learning they use. Researchers argue that academic stress in first-year students of the Faculty of Nursing, University of Jember is not only influenced by self-regulation learning, but there are several other factors both internal and external factors. However, students are expected to always use and pay attention to their learning strategies in the face of academic demands and are expected to further improve self-regulation in their learning in each teaching and learning process, so that students can meet academic achievements or targets structurally and get more optimal results.

\section{CONCLUSION}

The conclusion of this study is that self-regulation learning in first year students $(n=126)$ shows that most of them have a high level of self-regulation learning as many as 82 students $(65.1 \%)$. At the level of academic stress, most of the first year students experienced low levels of academic stress (29.4\%) to moderate academic stress (29.4). There is a relationship between self-regulation learning and academic stress in first year students of the Faculty of Nursing, University of Jember. The negative correlation results indicate that the higher the self-regulation learning, the lower the academic stress. Suggestions for this research for first year students are expected to be able to maintain and improve the learning process of self-regulation by planning learning activities well and structured. For further researchers, they can conduct research by providing interventions to improve self-regulation learning through psychological interventions (self-regulation learning training).

\section{ACKNOWLEDGEMENT}

Researchers thank all parties involved who have contributed to this study, one of them is a first-year student in 2020/2021, Faculty of Nursing, University of Jember who has cooperated well so that this research can be carried out smoothly and run well.

\section{REFERENCES}

American College Health Association. (2018). American College Health Association-National Collage Health Assessment II: Reference Group Executive Summary Fall 2018. Silver Spring, MD: American College Health Association.https://www.acha.org/documents/ncha/NCHA-II_Fall_2018_Reference_Group_Executive_Summary.pdf [Accessed on October 20, 2020].

Arabzadeh, M., F. Nikdel, K. P., K. J., and H. Katauoon. (2012). The relationship of self-regulated learning and self-efficacy with academic stress in university students. International Journal of Education. 2(2), 102-113.

Barseli, M., I Ifdil, and N. Nikmarijal. (2017). The concept of student academic stress. Journal of Counseling and Education. 5(3), 143-148.

Dami, ZA and P. Parikaes. (2018). Self-regulation learning as a consequence. Journal of Educational Research and Development. 1(1), 82-95.

Damri, Engkizar, and A. Fuady. (2017). The relationship between student self-efficacy and academic procrastination in completing lecture assignments. Educational Journal. 3(1), 74-95.

Friskilia, O. and W. Hendri. (2018). Self-regulation (self-regulation) as a determinant of vocational high school student learning outcomes. Journal of Office Management Education. 3(1), 36-43.

Gufron, MM and RS Risnawita. (2010). Psychological Theories. Yogyakarta: Ar-Ruzz Media.

Ministry of Education and Culture of the Republic of Indonesia. 2020. The Minister of Education and Culture Issues SE Concerning the Implementation of Education in the Covid-19 Emergency Period. Jakarta

Nurfitriana. (2016). Self-Adjustment in First Year Students at the Faculty of Psychology, University of Muhammadiyah Surakarta. Thesis. Page of the Faculty of Psychology, University of Muhammadiyah Suraka.

Pattynama, PC, R. Sahrani, and PH Heng. (2019). The role of self-regulation learning and academic involvement in the intention to 
resign with resilience as a mediator. Muara Journal. 3(2), 307-317.

Rahmawati, R. (2020). Self-regulation Learning and Academic Stress in Students. Thesis. Indonesian Islamic University.

Rena, S. (2018). Spirituality and Self-Regulation: Study of Stress Coping in Medical Faculty Students in DKI Jakarta. Thesis. Syarif Hidayatullah State Islamic University, Jakarta.

Sagita, DD, Daharnis, and Syahniar. (2017). The relationship between self-efficacy, achievement motivation, academic procrastination and student academic stress. Bikotik Journal. 01(02), 43-52.

Saniskoro, BSR and SZ Akmal. (2017). The role of adjustment in higher education towards academic stress in overseas students in Jakarta. Journal of Ulayat Psychology. 4(1), 95-106.

Saraswati, PUT, G. Antari, and Saputra. (2020). Relationship Of Parent-Child Communication With Stress Undergraduate Nursing and Nursing Profession Fk Unud. Community of Publishing in Nursing. 8(3), 268-273.

Sudarsana, AMY Lestari, WB Wijaya, A. Krisdayanthi, Y. Andayani, Trisnadewi, Muliar, S. Dewi, Suparya, D. Gunawan, NA Kusumawati, Y. Purandina, Sutriyanti, N. Sudiani, W. Adnyani, F. Iragraha , A. Winaya, A. Siswadi, and P. Aryana. (2020). COVID-19: Educational Perspectives. Bali: Our Writing Foundation.

Trevisani, C. (2015). A Correlational Study of Self-Regulated Learning, Stress and Mindfulness In Undergraduate Students. King's University College at Western University London, Canada.

Wistarini, NI and A. Marheni. (2018). The Role of Family Social Support and Self-Efficacy Against Academic Stress for New Students of the Faculty of Medicine, Udayana University Batch 2018. Journal of Psychology Udayana. 164-173.

Yusuf, NM and MY Jannatul. (2020). Factors influencing academic stress. Psyche Journal. 13(02), 4-5. 